JÓZEF GRZYWACZEWSKI, LEON NIEŚCIOR, WARSZAWA

ORCID: 0000-0003-4464-5145; ORCID: 0000-0003-4988-9667

\title{
MAREK EREMITA: BIOGRAFIA I BIBLIOGRAFIA
}

Marek Eremita, nazywany także Markiem Mnichem albo Markiem Ascetą, reprezentuje greckie środowisko monastyczne. Marek Starowieyski zauważa, że chociaż „ważnym pisarzem ascetycznym pochodzącym z Azji Mniejszej jest Marek Eremita", to jednak jego tożsamość pozostaje trudna do określenia". ${ }^{1}$ Według Nicefora C. Xantopulosa był on uczniem św. Jana Chryzostoma. ${ }^{2}$ Czas i miejsce jego działalności nie są pewne. Autor wielotomowego podręcznika z patrologii, J. Quasten, opowiadał się za hipotezą, że Marek był przełożonym klasztoru w Ancyrze w Galacji (obecnie Turcja), a potem udał się na pustynię w Judei, aby tam wieść życie pustelnicze. Prawdopodobnie zmarł po 430 r. ${ }^{3}$ Niektórzy z kolei przypuszczali, że mógł pochodzić z Syrii bądź Mezopotamii, ponieważ jego pisma cieszyły się popularnością na Wschodzie. ${ }^{4}$ Wybitny znawca tej postaci, O. Hesse, twierdzi jednak coś innego, ukazując różnice i podobieństwa w nauczania Marka Eremity i Szymona z Mezopotamii. ${ }^{5}$

1 Zob. M. S t a r ow i e y s k i, Literatura monastyczna, w: H. P o d b i e l s k i (red.), Literatura Grecji starożytnej. Proza historyczna, krasomówstwo, filozofia i nauka, literatura chrześcijańska, Lublin 2005, t. 2, s. 1123; H. C h a d w i c k, The identity and date of Mark the Monk, Eastern Churches Review 4/1972, s. 125-130.

2 Zob. Nicefori Callist i Xanthopuli, Ecclesiasticae historiae libri XVIII, księga XIV, 30.

3 Zob. J. Q u a s t e n, Initiation aux Pères de l'Église, tłum. J. L a p o r t e, Paris 1962, t. 3, s. 705.

4 Zob. Marc 1 e Mo in e, Traités, SCh 445, Wstęp, s. 25.

5 Zob. O. Hes s e, Markos Eremites und Symeon von Mesopotamien. Untersuchung und Vergleich ihrer Lehre zur Taufe und Askese, Göttingen 1973. 
Według niego większość danych wskazuje na IV/V w. i egipską pustynię jako czas i miejsce Markowej działalności. Marek Eremita był być może ,starcem” w środowisku pustelników, żyjącym w czasach między Soborem I Konstantynopolitańskim w 381 r. a Soborem Efeskim w 431 r. ${ }^{6} \mathrm{Na}$ Wschodzie jest czczony jako święty.

Marek Eremita napisał podobno ok. czterdziestu dzieł, ale zachowało się tylko dziesięć uznawanych dzisiaj za autentyczne. Poza dziełkiem Adversus Nestorianos, zostały wydane w serii Migne'a (PG 65, 905-1140). Do dorobku pisarskiego Marka Eremity nie zalicza się już dziełka De temperantia, które dzisiaj zgodnie uważa się za nieautentyczne, ${ }^{7}$ przez Migne'a jeszcze wydane pod jego imieniem. Razem z francuskim tłumaczeniem opublikowano je wszystkie w najnowszej, krytycznej edycji, w tomie 445. i 455. serii „Sources Chrétiennes". Poniżej zamieszczamy wykaz bibliografii źródłowej oraz w miarę kompletną literaturę przedmiotu.

Focjusz (†895) napisał o Marku Eremicie: „Przeczytaliśmy dzieło Marka Mnicha w ośmiu księgach. Pierwsza z nich otrzymała tytuł «O prawie ducha». Jest ona pożyteczna dla tych, którzy wybrali życie ascetyczne". ${ }^{8}$ Focjusz nie podał tytułów pozostałych ksiąg, lecz krótko je streścił. Na zakończenie omówił księgę De Melchisedech. Zapewne nie miał dzieła De incarnatione, opracowanego w celu zwalczania nestorianizmu. Sąd Focjusza o Marku jako pisarzu jest bardzo wyważony: „Styl dzieła jest jasny i zwięzły, kiedy autor posługuje się słownictwem potocznym; nie jest wcale ścisły, gdy używa języka attyckiego. Jeśli dostrzega się gdzieś miejsca niejasne, wynika to stąd, że same treści, z ich natury, rozumie się raczej w działaniu, a wymykają się one wyrażeniu ich słowami; nie wynika to bynajmniej

${ }_{6}$ Zob. t e n ż e, Markus Eremita. Asketische und dogmatische Schriften. Wstęp. Stuttgart 1985, s. 106.

7 Zob. tamże, s. 35.

8 F o c ju s z, Biblioteka, kodeks 200, tłum. O. J u r e w i c z, Warszawa 1988, t. 2, s. 154 . 
z trudności wyrażenia ich słowami”. ${ }^{9}$ Focjusz w zwięzły i trafny sposób określił zwięzłość i trafność języka charakteryzowanego pisarza.

Zdumiewająca jest wypowiedź Focjusza, gdy chodzi o ostatnią księgę: „W dziewiątej autor, zwalczając melchizedecytów, sam popada w ciężką herezję. Mimo to lektura tej książki nie pozostanie bezużyteczna dla tego, kto nastawia się na szukanie pożytku". ${ }^{10}$ G. M. de Durand, autor współczesnego wydania dzieł Marka Eremity, zaznacza, że jeśli nawet Focjusz pisze o „ciężkiej herezji” Eremity, to w rzeczywistości nie była ona wielka, a chodzi raczej o kilka wyrażeń, w których można by się dopatrzeć elementów monarchianistycznych. ${ }^{11}$

Niektórzy podejrzewali Marka Eremitę o mesalianizm. ${ }^{12}$ Zwolenników tego ruchu nazywano mesalianami - od syryjskiego słowa mesalaim oznaczającego człowieka modlącego się - albo euchitami,

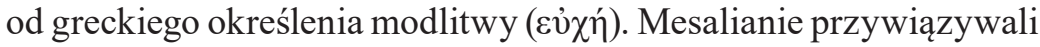
dużą wagę do modlitwy, akcentując znaczenie modlitwy ustnej, wypowiadanej głośno, oraz modlitwy nieustannej. Ich zdaniem człowiek po grzechu pierworodnym został tak opanowany przez szatana, że ani chrzest, ani inne sakramenty nie są w stanie uwolnić od niego całkowicie. Może w nim mieszkać jednocześnie zarówno Bóg, jak i szatan. Dopiero Duch Święty, sprowadzony przez ascezę i modlitwę nieustanną, wyzwala od szatana, namiętności i doprowadza do przebóstwienia. Podejrzenia Marka Eremity o mesalianizm nie dają się potwierdzić konkretnymi tekstami w tych jego dziełach, którymi dysponujemy. Wprost przeciwnie, jedno z nich, De baptismo, jest uznawane za wprost antymesaliańskie. ${ }^{13}$

Wpływ Marka Eremity na potomnych był dość znaczny. A. Torrance wskazuje, że w kręgu tego wpływu znaleźli się tacy pisarze jak Doroteusz z Gazy, Jan Klimak, Izaak Syryjczyk, Teodor Studyta,

\section{Tamże.}

10 Tamże, s. 155. Częściej używa się formy: melchizedekianie.

1 Zob. Marc le Moine, Traités. Wstep, s. 21.

12 Zob. Ph. E s c o l a n, Monachisme et l'Église. Le monachisme syrien du IVe au VIIe siècle: un monachisme charismatique, Théologie Historique 109/1999, s. 92.

13 Zob.tamże, s. 114; K. W a r e, The Sacrament of Baptism and the Ascetic Life in the Teaching of Mark the Monk, Studia Patristica 10/1970, s. 442. 
Szymon Nowy Teolog, Piotr z Damaszku, Grzegorz z Synaju, Grzegorz Palamas i Nikodem ze Świętej Góry. ${ }^{14}$ Autor ten był szczególnie znany w środowisku syryjskim. Należy do grona wybitnych pisarzy ascetycznych starożytności.

Na gruncie polskim Marek Eremita jest mało znany. Jak wynika z poniższej bibliografii, spośród dziesięciu zachowanych jego pism tylko dwa są przetłumaczone na język polski: O prawie duchowym i $O$ poście. Przekład pierwszego z nich, mianowicie sztandarowego dziełka Marka Eremity, jest dostępny w Internecie. ${ }^{15} \mathrm{~W}$ aktualnym zeszycie „Collectanea Theologica” publikujemy teksty polskich patrologów, które przybliżają nam istotne elementy jego nauki.

\section{Edycje tekstu}

De lege spiritali (O prawie duchowym), w: Marc le Moine. Traités; introd., texte critique, trad., notes et index par G. M. de Durand, SCh 445, Paris 1999, s. 74-129; PG 65, 905-929.

De his qui putant se ex operibus iustificari (O tych, którzy uważaja, że usprawiedliwia się na podstawie uczynków), wyd. i tłum.

G. M. de Durand, SCh 445, s. 130-201; PG 65, 929-965.

De paenitentia (O pokucie), wyd. i tłum. G. M. de Durand, SCh 445, s. 214-259; PG 65, 965-984.

De baptismo (O chrzcie), wyd. i tłum. G. M. de Durand, SCh 445, s. 296-397; PG 65, 985-1028.

Ad Nicolaum praecepta animae salutaria (Dla Mikołaja przykazania zbawienne dla duszy), wyd. i tłum. G. M. de Durand, SCh 455 (2000), s. 97-155; PG 65, 1028-1053.

14 Zob. A. Tor r a n c e, Repentance as the Context of Sainthood in the Ascetical Theology of Mark the Monk, w: P. C 1 a r k e, T. C 1 a y d o n (red.), Saints and Sanctity, Studies in Church History 47, Woodbrige 2011, s. 81.

15 Zob. http://bazhum.muzhp.pl/media//files/Slaskie_Studia_Historyczno_Teologiczne/Slaskie_Studia_Historyczno_Teologiczne-r2012-t45-n2/ Slaskie_Studia_Historyczno_Teologiczne-r2012-t45-n2-s257-272/Slaskie_Studia_Historyczno_Teologiczne-r2012-t45-n2-s257-272.pdf 
Disputatio cum causidico (Dyskusja z adwokatem), wyd. i tłum. G. M. de Durand, SCh 455 (2000), s. 27-93; PG 65, 1072-1101. Consultatio intellectus cum sua ipsius anima (Dialog intelektu z własna dusza), wyd. i thum. G. M. de Durand, SCh 445 (1999), s. 398-414; PG 65, 1104-1109.

De ieiunio (O poście), wyd. i tłum. G. M. de Durand, SCh 455, s. 158-166 (PG 65, 1109-1117.

De Melchizedech (O Melchizedeku), wyd. i tłum. G. M. de Durand, SCh 455, s. 171-223; PG 65, 1117-1140.

Adversus Nestorianos ( $=$ De incarnatione) (Przeciw nestorianom $=O$ wcieleniu , wyd. i tłum. G. M. de Durand, SCh 455, s. 253-314; wcześniejsze wydania: J. K u n z e (ed.), Marcus Eremita. Ein neuer Zeuge für das altkirchliche Taufbekenntnis, Leipzig 1895, s. 6-30; J. C o z z a - L u z i, Nova Patrum Bibliotheca, t. 10, Romae 1905, s. 195-252.

\section{Tłumaczenia}

Marc le Moine, Traités spirituels et théologiques, introd. par K. Ware; trad. française, notes et index par sœur C. A. Zirnheld, Bégrolles-en-Mauges 1985.

M a r o l'A s c et a, Discorsi sulla vita cristiana: tre opuscoli spirituali, ed. F. DiRossi, Torino 1986.

M a r o s el M o n j e, „Diálogo del espíritu con su alma”. Introd., trad. del texto y comment. de E. Contreras, C. Isla Casares, Cuadernos Monásticos 88/1989, s. 99-112.

Marku s Eremita, Asketische und dogmatische Schriften; eingeleitet, übersetzt und mit Anmerkungen versehen von O. Hesse, Stuttgart 1985, s. 153-347.

M a re k Ere m it a, św., O prawie duchowym, tłum. A. Jasiewicz, Śląskie Studia Historyczno-Teologiczne 45(2012) nr 2, s. $257-272$.

Mare k E re mit a, O poście, tłum. M. Warzocha i K. Żółtaszek, wstęp K. Żółtaszek, koment. M. Warzocha, Vox Patrum 67 (2017) nr 37, s. 813-823. 
Mark the Mon k, Counsels on the spiritual life: vol. 1 transl., with notes and introd. by T. Vivian; vol. 2 transl., with notes and introd. by T. Vivian and A. Casiday; foreword by R. Williams, Crestwood N.Y. 2009.

Tłum. ros. https://azbyka.ru/otechnik/Mark_Podvizhnik/.

\section{Opracowania}

C a rl t o n C., The „kyriakos anthropos” in Mark the Monk, Journal of Early Christian Studies 15(2007) nr 3, s. 381-405.

$\mathrm{C} \mathrm{h}$ a d w i $\mathrm{k} \mathrm{H}$., The Identity and Date of Mark the Monk, Eastern Churches Review 4/1982, s. 125-130.

$\mathrm{D}$ u $\mathrm{r}$ a $\mathrm{n}$ d G.-M. de, Vestiges d'une ancienne stichométrie des oeuvres de Marc l'Ascète, Revue d'histoire du droit 12-13/1982-1983, s. 371-380.

D u r a n d G. M. de, Études sur Marc le Moine: 1. L'épître à Nicolas, Bulletin de littérature ecclésiastique 85(1984) nr 4, s. 259-278.

D u r a nd G. M. de, Études sur Marc le Moine: 2. Le traité sur l'incarnation, Bulletin de littérature ecclésiastique 86(1985) nr 1, s. 5-23.

D u r a n d G.-M. de, Études sur Marc le Moine: 3. Marc et les controverses orientales, Bulletin de littérature ecclésiastique 87(1986) nr 3, s. 163-188.

D u r a n d G.-M. de, Études sur Marc le Moine: 4. Une double définition de la foi, Bulletin de littérature ecclésiastique 89(1988) nr 1, s. 23-40.

F a u r e E., Mémoire, connaissance et zèle dans le combat spirituel selon la Lettre à Nicolas attribuée à Marc le moine, Nouvelle Revue Théologique 139 (2017) nr 4, s. 605-618.

Gribomont J., Marc le Moine, Dictionnaire de Spiritualité 10/1980, s. 274-283.

G r i b o m o n t J., Marc l'Ermite et la christologie évagrienne, Cristianesimo nella storia 3(1982) nr 1, s. 73-81.

G r i b o m o n t J., Encore Marc l'Ermite: l'union selon l'hypostase, Cristianesimo nella storia 5(1984) nr 3, s. 463-473. 
Grill m e i e r A., Marco Eremita e l'origenismo: saggio di reinterpretazione di Op. XI, Cristianesimo nella storia 1(1980) nr 1, s. 9-58.

Gri $11 \mathrm{~m}$ e i e r A., Markos Eremites und der Origenismus: Versuch einer Neudeutung von Op. XI, w: F. Paschke i in. (red.) Überlieferungsgeschichtliche Untersuchungen, Berlin 1981, s. $253-283$.

H e s s e O., Markus Eremita und seine Schrift „,De Melchisedech”, Oriens Christianus 51/1967, s. 72-77.

$\mathrm{H}$ e s s e O., Erwägungen zur Christologie des Markus Eremita. Die Datierung seines Op. XI, w: Göttinger Arbeitskreis für syrische Kirchengeschichte (red.), Paul de Lagarde und die syrische Kirchengeschichte, Göttingen 1968, s. 90-101.

H e s s e O., Markos Eremita in der syrischen Literatur, w: W. Voigt (red.), Deutscher Orientalistentag vom 21. bis 27 Juli 1968 in Würzburg. Vorträge, Wiesbaden 1969, s. 450-457.

$\mathrm{H}$ e s s e O., Markos Eremites und Symeon von Mesopotamien: Untersuchung und Vergleich ihrer Lehren zur Taufe und Askese, Gottingen 1973 [Dissert.].

He s s e O., Was Mark the Monk a Sixth-Century Higumen near Tarsus? Eastern Churches Review 8(1976) nr 2, s. 174-178.

H e s s e O., Das Böse bei Markos Eremites, w: Makarios-Symposium über das Böse. Vorträge der Finnisch-deutschen Theologentagung in Goslar 1980, Wiesbaden 1983, s. 109-122.

H e s s e O., Der Streit über die Wirkung der Taufe im frühen Mönchtum bei Makarios/Symeon, Markos Eremites und den Messalianern, w: D. Hellholm, T. Vegge, Ø. Norderval, C. Hellholm (red.), Ablution, Initiation, and Baptism: Late Antiquity, Early Judaism, and Early Christianity, Berlin-Boston 2011, s. 1305-1345.

Jü s s e n K ., Dasein und Wesen der Erbsünde nach Markus Eremita, Zeitschrift für Katholische Theologie 62/1938, s. 76-91.

$\mathrm{K}$ a c z y n sk i B. M., A ninth-century Latin translation of Mark the Hermit's Peri nomu pneumatiku: Dresden, Sächsische 
Landesbibliothek, Mscr. A 145b, Byzantinische Zeitschrift 89(1996) nr 2, s. 379-388.

$\mathrm{K}$ h a 1 i fé I. A., L'antropologie théologique de Marc l'Ermite. De l'esclavage intérieur à la liberté spirituelle, Roma 1949.

$\mathrm{K}$ h a 1 i fé I. A., L'inauthenticité du „De Temperantia” (kephalaia nēptiká) de Marc l'Ermite, w: Mélanges de l'Université St. Jospeh Beyrouth 28, Beirut 1949/1950, s. 61-11.

$\mathrm{K} \mathrm{h}$ a $\mathrm{l}$ i fé I. A., Les traductions arabes de Marc l'Ermite, w: Mélanges de l'Université St. Jospeh Beyrouth 28, Beirut 1949/1950, s. 117-224.

K r ü g e r P., Überlieferung und Verfasser der beiden Memre über das geistige Gesetz des Mönches Markus, Ostkirchliche Studien 6/1957, s. 297-299.

K r ü g e r P., Zum theologischen Menschenbild Babais den Großen nach seinem noch unveröffentlichten Kommentar zu den beiden Sermones des Mönches Markus über Das geistige Gesetz, Oriens Christianus 44/1960, s. 46-74.

K r ü g e r P., Cognitio sapientiae. Die Erkenntnis der Wahrheit nach den unveröffentlichten beiden Sermones Babais des Großen über das geistige Gesetz des Mönches Markus, Studia Patristica 5/1962, s. 377-381.

K u n z e J., Marcus Eremita. Ein neuer Zeuge für das altkirchliche Taufbekenntnis: eine Monographie zur Geschichte des Apostolikums mit einer kürzlich entdeckten Schrift des Marcus, Leipzig 1895.

K u n z e J., Marcus Eremita und Hieronymus, Theologisches Literaturblatt 19 (1898) nr 34, s. 393-398.

L e b o n J., Le moine saint Marcien. Étude critique des sources. Édition de ses écrits, Louvain 1968.

M a n z i F., Il fascino di Melchisedek su Marco il Monaco, Ephemerides liturgicae 115(2001) nr 4, s. 488-503.

P e te r s on E., Die Schrift des Eremiten Markus über die Taufe und die Messalianer, Zeitschrift für die Neutestamentliche Wissenschaft 3/1932, s. 273-289. 
To r r a n e A., Repentance in late antiquity: eastern asceticism and the framing of the Christian life c. 400-650 CE, Oxford 2013.

W a r e K., The Ascetic Writings of Mark the Hermit, Oxford 1965 (mps).

W a r e K., The Sacrament of Baptism and the Ascetic Life in the Teaching of Mark the Monk, Studia Patristica 10/1970, s. 441-452.

Z aj c ev I., Svjatootečeskoe učenie o glavnych momentach postepennogo razvitija grecha (sv. Ioann Lestvičnik, sv. Ioann Kassian, sv. Diadoch i sv. Mark Podwižnik), Moskau 1959 (mps). 